\title{
PENGARUH MOTIVASI TERHADAP PENINGKATKAN PRESTASI KARYAWAN PADA P.T. TRIO KENCANA ABADI BANDAR LAMPUNG
}

\author{
Rana Ashillah Ghaliavisa $\left({ }^{1}\right)$, Husna Purnama ${ }^{(2)}$, Maria Elina ${ }^{(3)}, \operatorname{Hesti~Widi~Astuti~}^{(4)}$ \\ Universitas Sang Bumi Ruwa Jurai
}

ranaashilla@gmail.com,husnapurnama@gmail.com,mariasaburai3@gmail.com, hesti172112@gmail.com

\begin{abstract}
Abstrak: Permasalahan dalam penelitian ini adalah kecilnya penghargaan/reward yang diberikan perusahaan berdampak pada semangat kerja karyawan bagianpemasaran menurun serta target penjualan yang tinggi yang membebani karyawanbagian pemasaran yang tidak diiringi dengan pemberian motivasi yang memadai berdampak pada penurunan volume penjualan. Tujuan penelitian untuk mengetahui pengaruh motivasi terhadap peningkatan prestasi kerja karyawan pada P.T. Trio Kencana Abadi Bandar Lampung. Metode penelitian yang digunakan dalam penelitian ini menggunakan metode penelitian deskriptif kualitatif dan kuantitatif. Metode pengumpulan data yang digunakan berupa data primer dan data sekunder. Teknik pengumpulan data yang digunakan adalah observasi dan kuisioner. Sampel akan ditentukan dari jumlah populasi sebanyak 34 karyawan P.T. Trio Kencana Abadi Bandar Lampung. Hasil pengujian hipotesis pengaruh Motivasi (X) terhadap Prestasi kerja menunjukan

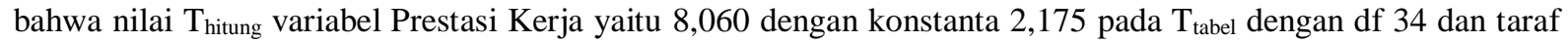
signifikan 0,05 diperoleh 1,691 karena $\mathrm{T}_{\text {hitung lebih besar dari }} \mathrm{T}_{\text {tabel }}$ maka Ha diterima. Signifikasi variabel motivasi adalah 0,000 yang berarti probabilitas 0,000 , karena probabilitas kurang dari 0,05maka Ha diterima. artinya motivasi berpengaruh terhadap Prestasi Kerja.
\end{abstract}

Kata Kunci : Motivasi, Prestasi Kerja, Karyawan.

\begin{abstract}
The problem in this study is that the small amount of rewards given by the company has an impact on the morale of marketing employees decreasing and high sales targets that burden marketing employees who are not accompanied by adequate motivation, resulting in a decrease in sales volume. The purpose of the study was to determine the effect of motivation on improving employee performance at P.T. Trio Kencana Abadi Bandar Lampung.The research method used in this research is descriptive qualitative and quantitative research methods. Data collection methods used in the form of primary data and secondary data. Data collection techniques used are observation and questionnaires. The sample will be determined from a total population of 34 employees of P.T. Trio Kencana Abadi Bandar Lampung. The results of testing the hypothesis of the influence of motivation (X) on work performance show that the Tcount value of the Work Achievement variable is 8.060 with a constant of 2.175 in T-table with df 34 and a significant level of 0.05 obtained 1.691 because Tcount is greater than Ttable, then $\mathrm{Ha}$ is accepted. The significance of the motivation variable is 0.000 , which means the probability is 0.000 , because the probability is less than 0.05, then Ha is accepted. it means that motivation has an effect on work performance.
\end{abstract}

Keywords: Motivation, Work Performance.

\section{PENDAHULUAN}

Pengelolaan sumber daya manusia tidak terlepas dari faktor karyawan yang dapat diharapkan berprestasi sebaik mungkin demi mencapai tujuan organisasi. Karyawan merupakan aset utama organisasi dan mempunyai peran yang strategis didalam organisasi yaitu pemikir, perencana, dan pengendali aktivitas organisasi demi tercapainya tujuan organisasi, karyawan memerlukan motivasi untuk bekerja lebih rajin. Melihat pentingnya karyawan dalam organisasi, maka karyawan memerlukan perhatian lebih serius terhadap tugas yang dikerjakan sehingga tujuan organisasi tercapai. Dengan motivasi kerja yang tinggi karyawan akan bekerja lebih giat didalam melaksanakan pekerjaannya. Sebaliknya 
dengan motivasi kerja yang rendah karyawan tidak mempunyai semangat bekerja, mudah menyerah, dan kesulitan dalam menyelesaikan pekerjaannya.

Motivasi karyawan tidak terlepas dari peran serta dari seorang pemimpin dalam membina bawahannya. Seorang pemimpin dapat dikatakan berhasil memotivasi para karyawan dengan dapat dilihat dari tingkah lakudan sikap karyawan terhadap pekerjaan yang dilakukannya, yaitu apakah mereka bekerja dengan sungguh-sungguh bersemangat dan tidak terlihat sifatterpaksa dalam melaksanakan tugas-tugasnya. Dalam memotivasi karyawan agar kinerjanya meningkat dapat dilakukan dengan berbagai cara diantaranya, dengan memenuhi kebutuhan dan keinginan karyawan diantaranya dapat dilakukan dengan memberikan upah yang cukup memberikan insentif yang wajar, memberikan penghargaan kepada karyawan yang berprestasi, serta menyediakan fasilitasfasilitas yang mendukung kegiatan.

P.T. Trio Kencana Abadi Bandar Lampung merupakan dealer utama sepeda motor Honda di Lampung yang beralamatkan di Jl. Yos Sudarso Nomor 180 Panjang, Bandar Lampung. PT. Trio Kencana Abadi Bandar Lampung memiliki karyawan Bagian Pemasaran berjumlah 34 karyawan. Berikut data Karyawan P.T. Trio Kencana Abadi Bandar Lampung dapat dilihat pada tabel 1 di bawah ini:

Tabel 1.

Data Karyawan PT. PT. Trio Kencana Abadi Bandar Lampung Tahun 2019

\begin{tabular}{lll}
\hline Departemen & Posisi / Jabatan & Jumlah \\
\hline Pemasaran & Manajer Pemasaran & 1 \\
\cline { 2 - 2 } & $\begin{array}{l}\text { Wakil Manager } \\
\text { Pemasaran }\end{array}$ & 1 \\
\cline { 2 - 2 } & Koordinator Pemasaran & 1 \\
\cline { 2 - 2 } & Sales Counter & 5 \\
\cline { 2 - 2 } & Sales & 15 \\
\cline { 2 - 2 } & Surveyer & 7 \\
\cline { 2 - 2 } & Driver & 4 \\
\cline { 2 - 2 } & Jumlah & $\mathbf{3}$ \\
& $\mathbf{4}$ \\
\hline
\end{tabular}

Sumber : PT. Trio Kencana Abadi Bandar Lampung, 2020

Dari tabel 1 menunjukan jumlah karyawan Bagian Pemasaran P.T. Trio Kencana Abadi Bandar Lampung berjumlah 34 karyawan yang terdiri atas manajer pemasaran, wakil manajer pemasaran dan koordinator pemasaran sebanyak 3 orang,kemudian sales counter sebanyak 5 orang, sales sebanyak 15 orang, surveyor sebanyak 7 orang dan driver sebanyak 4 orang.

Indikator Keberhasilan perusahaan dalam menghadapi persaingan adalah Kebijakan, meliputi penentuan harga, pemilihan produk, penetuan promosi paling efektif dan efisien, dan pemilihan saluran distribusi yang paling tepat. Penerapan kebijakan di atas secara tepat akan mempengaruhi perilaku konsumen dalam untuk memberli produk perusahaan sehingga pada akhirnya akan meningkatkan jumlah penjualan. Keberhasilan kegiatan pemasaran tak terlepas dari sumber daya manusia yaitu orang-orang yang menyediakan tenaga, bakat, kreativitas dan semangat bagi organisasi sertamemegang peranan penting dalam fungsi operasional 
Tabel 2.

Volume Penjualan Kendaraan Bermotor PT. Trio KencanaAbadi di Bandar Lampung Tahun 2019

\begin{tabular}{llc}
\hline No & Bulan & Volume Unit \\
\hline 1. & Januari & 97 \\
2. & Februari & 103 \\
3. & Maret & 118 \\
4. & April & 104 \\
5. & Mei & 160 \\
6. & Juni & 86 \\
7. & Juli & 125 \\
8. & Agustus & 130 \\
& & \\
9. & September & 103 \\
10. & Oktober & 111 \\
11. & November & 125 \\
12. & Desember & 133 \\
\hline Jumlah & & 1395 \\
\hline
\end{tabular}

Sumber : PT. Trio Kencana Abadi, 2020.

Berdasarkan data tabel 2 diketahui total volume penjualan kendaraan bemotor pada tahun 2019 sebanyak 1395 unit. Volume penjualan tiap bulan dalam tahun 2019 berfluktuasi (naik/turun). Penjualan kendaraan bermotor tertinggi terjadi pada Bulan Mei tahun 2019 sebanyak 160 unit. Sedangkan terendah terjadi pada bulan Juni 2019 sebanyak 86 unit. Hal ini mengindikasikan bahwa semangat kerja karyawan bagian kurang optimal.

Usaha untuk membina mendorong dan mengarahkan karyawan perlu dilakukan untuk dapat meningkatkan prestasi kerja, karena prestasi kerja merupakan faktor penentu bagi kelancaran organisasi dan menentukan tingkat keberhasilan pemerintahan dalam mencapai tujuannya. Prestasi kerja yang terarah dan dilandasi mutu serta ketrampilan yang tinggi akan menghasilkan kerja yang efektif dan efisien, yang dengan demikian prestasi kerja karyawan itu menentukan tingkat keberhasilan organisasi dalam mencapai tujuan. Peningkatan prestasi kerja karyawan bukanlah suatu hal yang timbul begitu saja dari karyawan, tetapi di pengaruhi oleh berbagai faktor, seperti motivasi kerja karyawan merupakan faktor yang tidak dapat diabaikan. Tanpa motivasi kerja yang tinggi, karyawan tidak akan mendapat dorongan dan hanya menunggu perintah dan kurang inisiatif dan kurang tanggung jawab. Rumusan masalah dalam penelitian ini adalah sebagai berikut : apakah motivasi berpengaruh terhadap prestasi karyawan pada P.T. Trio Kencana Abadi Bandar Lampung.

Teori maslow mengatakan bahwa kebutuhan manusia tersusun dari suatu hirarki. Tingkat kebutuhan yang paling rendah adalah kebutuhan fisiologis dan yang paling tinggi adalah kebutuhan aktualisasi diri. Lima (5) hirarki kebutuhan dasar manusia menurut maslow yaitu : (1) Kebutuhan fisiologis (Physiologocal needs), meliputi rasa lapar, haus, berlindung, seksual dan kebutuhan fisik lainnya; (2) Kebutuhan keamanan dan keselamatan kerja (Security or safety needs), meliputi rasa ingin dilindungi dari bahaya fisik dan emosional; (3) Kebutuhan sosial (Affiliation or acceptance needs), meliputi rasa kasih sayang, kepemilikan, penerimaan dan persahabatan; (4) Kebutuhan penghargaan (Esteem needs), meliputi penghargaan internal seperti hormat diri, otonomi dan pencapaiannya serta faktorfaktor penghargaan eksternal seperti status pengakuan dan perhatian; (5) Kebutuhan aktualisasi diri (Needs for self actualization), dorongan untuk menjadi seseorang sesuai kecakapannya meliputi pertumbuhan, pencapaian potensi seseorang dan pemenuhan diri sendiri.

Maslow mengasumsikan bahwa orang berusaha memenuhi kebutuhan yang lebih pokok (fisiologis) sebelum mengarahkan perilaku kearah kebutuhan yang paling tinggi (self actualization). Apabila 
kebutuhan seseorang (pegawai) sangat kuat, maka semakin kuat pula motivasi orang tersebut menggunakan perilaku yang mengarah pada pemuasan kebutuhannya.

Ukuran terakhir keberhasilan dari suatu organisasi adalah prestasi kerja. Karena baik departemen itu sendiri maupun karyawan memerlukan umpan balik atas upayanya masing-masing, maka prestasi kerja dari setiap pegawai perlu dinilai. Oleh karena itu penilaian prestasi kerja, Menurut Heidarahman dan Husnan, (2012), faktorfaktor prestasi kerja yang perlu dinilai adalah sebagai berikut: (1) Kuantitas Kerja : Banyaknya hasil kerja sesuai dengan waktu kerja yang ada, yang perlu diperhatikan bukan hasil rutin tetapi seberapa cepat pekerjaan dapat diselesaikan; (2) Kualitas Kerja : Mutu hasil kerja yang didasarkan pada standar yang ditetapkan.Biasanya diukur melalui ketepatan, ketelitian, keterampilan, keberhasilan hasil kerja; (3) Keandalan :Dapat atau tidaknya pegawai diandalkan adalah kemampuan memenuhi atau mengikuti instruksi, inisiatif, hati-hati, kerajinan dan kerjasama; (4) Inisiatif : Kemampuan mengenali masalah dan mengambil tindakan korektif, memberikan saran-saran untuk peningkatan dan menerima tanggung jawab menyelesaikan; (5) Kerajinan : Kesediaan melakukan tugas tanpa adanya paksaan dan juga yang bersifat rutin; (6) Sikap : Perilaku pegawai terhadap organisasi atau atasan atau rekan kerja, (7) Kehadiran : Keberadaan pegawai di tempat kerja untuk bekerja sesuai dengan waktu / jam kerja yang telah ditentukan.

Penelitian terdahulu dalam penelitian ini adalah (1) Pengaruh Motivasi Terhadap Prestasi Kerja Pegawai Dinas Komunikasi Dan Informatika Kota Bandung, hasil penelitiannya sebagai berikut bahwa terdapat pengaruh yang besar antara motivasi terhadap prestasi kerja pegawai. Sedangkan faktor lain yangtidak terdefinisi, cukup mempengaruhi variabelprestasi kerja pegawai, selainvariabel motivasi (Supriadi,
2016); (2) Hubungan Motivasi Dan KompetensiDengan Kinerja Pegawai Pada Kantor Kecamatan Katibung Kabupaten Lampung Selatan (Purnama, H. 2017), hasil penelitiannya adalah sebagai berikut: Pengujian hipotesis hubungan motivasi dan kompetensi dengan kinerja pegawai pada kantor kecamatan Katibung kabupaten Lampug Selatan dengan 49 responden sebagai pegawai, Adanya hubungan positif sedang antara Motivasi $\left(\mathrm{X}_{1}\right)$ terhadap Kinerja pegawai (Y) yang dibuktikan dengan nilai $\mathrm{R}=0,66$ hal ini berarti jika Motivasi $\left(\mathrm{X}_{1}\right)$ naik maka Kinerja pegawai (Y) akan naik. Adanya hubungan positif antara Kompetensi $\left(\mathrm{X}_{2}\right)$ terhadap Kinerja pegawai (Y) yang dibuktikan dari hasil analisis $\mathrm{R}=0,67$ yang menunjukkan jika Kompetensi $\left(\mathrm{X}_{2}\right)$ meningkat maka Kinerja pegawai (Y) akan meningkat; (3) Pengaruh Reward, Kepuasan Kerja Dan Motivasi Kerja Terhadap Kinerja Karyawan(Studi LeasSing Adira Finance Syariah), hasil penelitian rewardmemiliki pengaruh positif terhadap kinerja karyawan. kepuasan kerja kurang berpengaruh terhadap kinerja karyawan sedangkan motivasi kerja memiliki pengaruhpositif terhadap kinerja karyawan. Berdasarkan hasil uji R Square pada menunjukkan bahwa nilai $\mathrm{R}$ Square sebesar 0,489 atau sama dengan 48,9\%. variabel reward, kepuasan kerja dan motivasi kerja terhadap kinerja karyawan adalah sebesar $48,9 \%$ sedangkan $51,1 \%$ di tentukan oleh faktor lain (http://repository.iainbengkulu.ac.id/3 289, 2019).

Hipotesis dalam penwlitian ini adalah diduga motivasi berpengaruh terhadap peningkatan prestasi karyawan pada P.T. Trio Kencana Abadi Bandar Lampung. 


\section{METODE PENELITIAN}

Objek dalam penelitian adalah Bagian Marketing pada PT. Trio Kencana Abadi Bandar Lampung. Variabel dalam penelitian yaitu motivasi adalah variable $\mathrm{X}$ dan prestasi kerja adalah variable $\mathrm{Y}$.

Metode pengumpulan data menggunakan data primer dan data sekunder. Teknik pengumpulan data dengan cara observasi, wawancara, kuisioner, dokumentasi dan kepustakaan.

Sampel dalam penelitian ini berjumlag 34responden. Aalat analisis yang digunakan adalah uji validitas digunakan untuk mengukur sah atau valid tidaknya suatu kuesioner (arikunto, 2006), uji reliabilitas merupakan alat untuk mengukur kehandalan, ketetapan atau keajegan atau konsistensi suatu kuesioner (Arikunto, 2006), Analisis regresi linear sederhana adalah suatu analisis yang mengukur antara variabel bebas (X) dan variabel (Y) (Sugiyono, 2011), Koefisien determinasi merupakan suatu nilai (nilai proporsi) yang mengukur seberapa besar kemampuan variabel-variabel bebas yang digunakan dalam persamaan regresi, dalam menerangkan variasi variabel tak bebas ( Ujarati, 2003); uji hipotesis.

\section{HASIL DAN PEMBAHASAN}

\section{HASIL}

Berdasarkan hasil pengujian validitas dengan aplikasi SPSS versi 20.0 hasil pengujian validitas motivasi adalah sebagai berikut :

Tabel 3

Uji Validitas Motivasi

\begin{tabular}{llll}
\hline Pertanyaan & $\begin{array}{c}\text { Nilai } \\
\mathrm{r}_{\text {hit }}\end{array}$ & $\begin{array}{c}\text { Nilai } \\
\mathrm{r}_{\text {tabel }}\end{array}$ & Keterangan \\
\hline 1 & 0.656 & 0.339 & Valid \\
\hline 3 & 0.890 & 0.339 & Valid \\
\hline 4 & 0.945 & 0.339 & Valid \\
\hline 5 & 0.876 & 0.339 & Valid \\
\hline 6 & 1.742 & 0.339 & Valid \\
\hline 7 & 0.656 & 0.339 & Valid \\
\hline 8 & 0.742 & 0.339 & Valid \\
\hline 9 & 0.639 & 0.339 & Valid \\
\hline 10 & 0.737 & 0.339 & Valid \\
\hline Sumber & 0.915 & 0.339 & Valid
\end{tabular}

Sumber: Data Diolah, 2020.

Penafsirkan hasil uji validitas, kriteria yang digunakan adalah Jika nilai $\mathbf{r}_{\text {hitung }}$ lebih besar dari $r_{\text {tabel }}$ maka item angket dinyatakan valid. Berdasarkan hasil uji validitas, angket Motivasi secara keseluruhan dinyatakan valid.

Berdasarkan hasil pengujian validitas dengan aplikasi SPSS versi 20.0 hasil pengujian validitas prestasi kerja adalah sebagai berikut:

Tabel 4 Uji Validitas Prestasi Kerja Sumber: Data Diolah, 2020 


\begin{tabular}{|c|c|c|c|}
\hline Item tes & Nilai $r_{h i t}$ & Nilai $r_{\text {tabel }}$ & Keterangan \\
\hline 1 & 0,829 & 0,339 & Valid \\
\hline 2 & 0,787 & 0,339 & Valid \\
\hline 3 & 0,872 & 0,339 & Valid \\
\hline 4 & 0,781 & 0,339 & Valid \\
\hline 5 & 0,832 & 0,339 & Valid \\
\hline 6 & 0,832 & 0,339 & Valid \\
\hline 7 & 0,710 & 0,339 & Valid \\
\hline 8 & 0,688 & 0,339 & Valid \\
\hline 9 & 0,861 & 0,339 & Valid \\
\hline 10 & 0,898 & 0,339 & Valid \\
\hline
\end{tabular}

Berdasarkan hasil uji validitas Prestasi Kerja, maka item angket volume penjualan secara keseluruhan dinyatakan valid.

Hasil perhitungan uji reliabilitas terhadap instrumen penelitian variabel Motivasi dan Prestasi Kerja menunjukkan adanya reliabel (kesesuaian) baik antara item pertanyaan maupun totalitas. Secara rinci diperlihatkan pada tabel berikut:

Tabel 5

Uji Reliabilitas Motivasi dan Prestasi Kerja

\begin{tabular}{lcl}
\hline \multicolumn{1}{c}{ Variabel } & Cronbach Alpha & \multicolumn{1}{c}{ Status } \\
\hline Motivasi & 0,945 & Reliabel \\
\hline Prestasi Kerja & 0,954 & Reliabel \\
\hline
\end{tabular}

Tabel 5 di atas, menunjukkan bahwa cronbach's alpha total untuk variabel Motivasi sebesar 0.945 lebih besar dari 0,404, sedangkan cronbach alpha untuk variabel Prestasi Kerja sebesar 0,954 lebih besar dari 0,404, jadi dapat dinyatakan bahwa seluruh kuisioner adalah reliabel.
Tabel 6 Uji Regresi Linier Sederhana

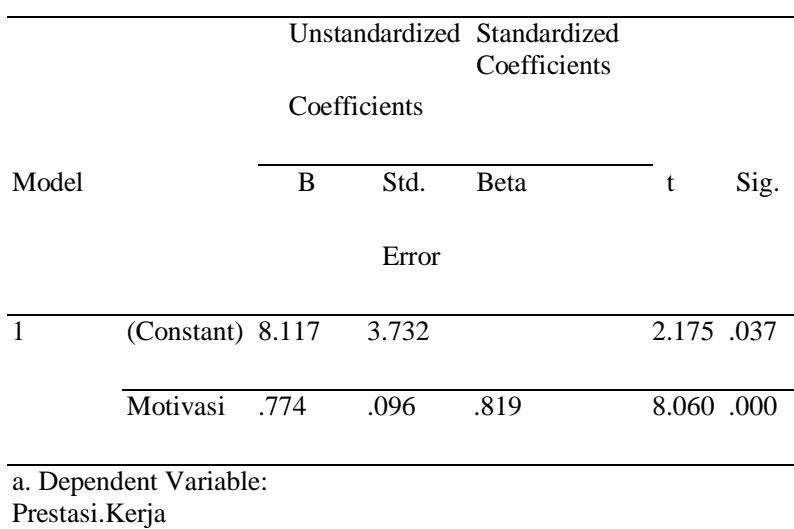

Sumber: Data Diolah, 2020.

Persamaan regeresinya adalah $\mathrm{Y}=8,117+$ $0,774 x$. Persamaan regresi tersebut terlihat bahwa pengaruh motivasi terhadap prestasi kerja arti bahwa setiap kenaikan Motivasi 1 satuan akan diikuti dengan kenaikan prestasi Kerja sebesar 0,774 satuan. Untuk menguji pengaruh motivasi terhadap prestasi kerja P.T. Trio Kencana Abadi, penulis menggunakan uji T.Apabila nilai thitung lebih besar dari tabel maka Ho ditolak dan $\mathrm{Ha}$ diterima. Sebaliknya apabila $t_{\text {htung }}$ kurang dari tabel maka Ho diterima dan Ha ditolak .

Tabel 7 Hasil uji Kooefisien Diterminasi

\begin{tabular}{|l|l|l|l|l|}
\hline Model & \multicolumn{1}{|c|}{$\mathrm{R}$} & $\mathrm{R}$ Square & $\begin{array}{r}\text { Adjusted } \\
\text { R Square }\end{array}$ & $\begin{array}{c}\text { Std. Error of } \\
\text { theEstimate }\end{array}$ \\
\hline 1 & $.819^{\mathrm{a}}$ & .670 & .660 & 2.101 \\
\hline
\end{tabular}

a. Predictors: (Constant), Motivasi

Sumber: Data Diolah, 2020

Dari tabel di atas diketahui bahwa kontribusi ( $R$ Square ) sebesar 0,670 artinya sebesar $67 \%$ variasi perubahan variabel prestasi kerja mampu dijelaskan oleh variabel motivasi sedangkan sisanya sebesar 33\% lagidijelaskan oleh variabel lain diluar dari variabel penelitian ini.

\section{PEMBAHASAN}

Motivasi merupakan faktor yang sangat menentukan dalam pencapaian prestasi kerja suatu karyawan. Menurut 
model penilaian prestasi kerjakaryawan dari Victor H. Vroom atau disebut Model Vroomean (Umar, 2009), prestasi kerja seorang bergantung pada motivasi dan kemampuan kerjanya atau dalam rumus $\mathrm{P}=$ M x A; P untuk prestasi, $\mathrm{M}$ untuk motivasi, dan A untuk kemampuan kerja dalam hal ini, motivasi ialah keinginan seseorang melakukan sesuatu karena memang dia menginginkan untuk melakukannya dan juga karena merasa wajib melakukan itu, selanjutnya dikatakan bahwa jika mereka termotivasi, mereka akan membuat pilihan positif untuk melakukan sesutu misalnya karena hal itu dapat memuaskan beberapa kebutuhan mereka; adapun, kemampuan kerja ialah kesanggupan, kecakapan, atau kekuatan yang dimiliki seseorang sebagai perwujudan dari pengetahuan dan keterampilan dalam suatu bidang kerja. Agar diperoleh prestasi kerja tertinggi yang dimungkinkan oleh tingkat kemampuan yang dimiliki para karyawan bukan merupakan pekerjaan tunggal melainkan hasil dari proses yang berbentuk siklus. Suatu model motivasi yang disebut Imbalan-Prestasi atau $A$ reward Performance dapat menggambarkan hal itu. Prestasi yang dihasilkan Hal ini dapat memuaskan karyawan karena imbalan yang diharapkan sesuaian dengan keinginan dan kebutuhan karyawan. Harapan atau kebutuhan orang mencakup banyak hal secara umum dapat dikelompokan menjadi 3 yaitu : kebutuhan fisik, kebutuhan sosial, kebutuhan egoistik. Akan tetapi Maslow dapat mengorganisasikan atau mengklasifikan kebutuhan manusia menurut prioritas. Semua kondisi yang memberi dorongan dari dalam diri seseorang yang digambarkan sebagai keinginan, kemauan, dorongan dan sebagainya disebut juga motivasi. Motivasi merupakan keadaan dalam diri seseorang yang mengaktifkan atau menggerakan. Dari pandangan seorang pimpinan, seseorang yang termotivasi, yakni akan bekerja keras, mempertahankan langkah kerja keras, dan memiliki perilaku yang dikendalikan sendiri ke arah sasaransasaran penting. Dengan kata lain, motivasi mencakup upaya, pantang mundur dari sasaran.

\section{KESIMPULAN}

Berdasarkan hasil penelitian diperoleh kesimpulan; (1) hasil uji regresi linier sederhana adalah motivasi berpeb $=$ ngaruh terhadap prestasi kerja karyawan, (2) hasil uji $\mathrm{T}$ sebagai berikut $\mathrm{t}$ hitung lebih besar dari $t$ tabel maka Ha diterima. Signifikasi variabel motivasi adalah 0.000 yang berarti probabilitas 0.000 , karena probabilitas kurang dari 0,05 maka Ha diterima. artinya motivasi berpengaruh positif terhadap Prestasi Kerja

\section{DAFTAR PUSTAKA}

Arikunto, S., 2006, Prosedur Penelitian: Suatu pendekatan Praktik. Jakarta, Rineka Cipta.

Heidjrachman, R. \& Husnan, S., 2012, Manajemen Personalia, Yogyakarta, BPFE

$\frac{\text { http://repository.iainbengkulu.ac.id/3289/ }}{\text { Nensi PermataSari }}$

http://repository.unpas.ac.id/11835/Hendri MochamadSupriadi

http://www.jurnal.saburai.ac.id/index. php/manajemen/article/view/52

Siagian, Sondang P. 2002. Manajemen Sumber Daya Manusia. Jakarta: PT Bumi Aksara 
Rana Ashillah Ghaliavisa : Pengaruh Motivasi Terhadap Peningkatan Prestasi Kerja Karyawan Pada P.T. Trio Kencana Abadi Bandar Lampung

Sugiyono.2007.Metode Penelitian

pedidikan pendekatan kuantitatif,

kualitatif, dan $R \& D$.Bandung:

Alfabeta. 